\title{
Chemotherapy management for unfit patients with metastatic castration-resistant prostate cancer
}

\author{
U. Anido-Herranz ${ }^{1}\left[\right.$ ] N. Fernández-Núñez ${ }^{2} \cdot$ J. Afonso-Afonso $^{3} \cdot$ L. Santomé-Couto ${ }^{4} \cdot$ A. Medina-Colmenero $^{5}$. \\ O. Fernández-Calvo ${ }^{6} \cdot$ M. Lázaro-Quintela ${ }^{7} \cdot$ S. Vázquez ${ }^{2}$
}

Received: 9 May 2018 / Accepted: 11 July 2018 / Published online: 26 July 2018

(c) The Author(s) 2018

\begin{abstract}
Administration of chemotherapy in prostate cancer depends on patient fitness. In unfit patients, physiological impairment determines the optimum treatment. Although no consensus on assessing patient fitness currently exists, this article proposes an algorithm combining the available information for administering chemotherapy, and in particular docetaxel, in unfit patients. It was constructed by reviewing factors that can influence treatment, such as performance status, taxane-related comorbidities and nutritional status. Geriatric scales for prostate cancer patients and alternative treatment regimens for this population are also reviewed. In summary, patients require overall assessment to optimise treatment. Use of docetaxel should be restricted in unfit patients, and other options must be evaluated, because of high toxicity and low efficacy.
\end{abstract}

Keywords Unfit patient $\cdot$ Comorbidity $\cdot$ Performance status $\cdot$ Alternative treatment

\section{Introduction}

There are 1.1 million new cases of prostate cancer every year worldwide and 307,000 deaths [1], but this incidence increases with age, and the disease coincides with various age-related conditions. The concept of "fitness" encompasses a person's physical condition, as well as their health and wellbeing. Conversely, the terms "frailty" or "unfitness" imply a state of cumulative impairment of the various

U. Anido-Herranz

urbanoanido@gmail.com

N. Fernández-Núñez

natalia.fernandez.nunez@sergas.es

J. Afonso-Afonso

francisco.javier.afonso.afonso@sergas.es

L. Santomé-Couto

1santome@povisa.es

A. Medina-Colmenero

anamedinacolmenero@yahoo.es

O. Fernández-Calvo

ovidiofernadezcalvo@sergas.es

M. Lázaro-Quintela martin.lazaro.quintela@sergas.es

S. Vázquez sergio.vazquez.estevez@sergas.es physiological systems within an individual, which depend on many factors. Therefore, physical condition or fitness among elderly patients will differ, and should be assessed on an individual basis.

The occurrence of serious adverse effects related to the administration of prostate cancer treatments, especially chemotherapy, is significantly related to worse performance status. The likelihood of treatment effectiveness or success in unfit patients will be influenced by these side effects,

1 Medical Oncology Department, Santiago University Hospital Complex (CHUS), Travesía de Coupana, s/n, 15706 Santiago de Compostela, Spain

2 Medical Oncology Department, Lucus Augusti University Hospital (HULA), Lugo, Spain

3 Medical Oncology Department, El Ferrol University Hospital Complex (CHUF), Ferrol, Spain

4 Medical Oncology Department, POVISA Hospital, Vigo, Spain

5 Medical Oncology Department, Centro Oncológico de Galicia, A Coruña, Spain

6 Medical Oncology Department, Ourense University Hospital Complex, Orense, Spain

7 Medical Oncology Department, Vigo University Hospital Complex (CHUVI), Vigo, Spain 
which prevent the administration of full doses and cause delays or complications that, in a worst-case scenario, may prove to be fatal. On the other hand, age itself should not be an exclusion factor, as a high proportion of the ageing population can benefit from these treatments. Moreover, physical function may be partly dictated by the disease itself, because some patients' physical condition will improve with the treatment.

It is therefore essential for each patient's fitness to be assessed on an individual basis, given that this is a highly heterogeneous population with considerable variation in cognitive and physical performance. In an attempt to standardise the assessment of fitness, various tools, geriatric scales and toxicity calculators have been proposed. However, there is no consensus on administering chemotherapy in this patient group.

This article describes a systematic review of the literature, bringing together the available information on administering chemotherapy, in particular docetaxel, in patients with prostate cancer, who should be treated according to their health status. Recommendations are made on how best to evaluate these patients, and which alternative treatment to provide to patients considered unfit.

\section{Factors to consider in prostate cancer treatment}

\section{Age}

Age is an important factor to be considered in prostate cancer, as $25 \%$ of patients are over 75 years old at diagnosis. Even at early tumour stages, mortality increases with age [2]. Moreover, this disease accounts for a third of cancer deaths in the over $80 \mathrm{~s}$ [3]. A number of determinants for geriatric patients have been incorporated into the recommendations of the International Society of Geriatric Oncology (SIOG) for the management of prostate cancer patients [4-6]. These guidelines advise performing an initial health assessment using the G8 tool, which includes eight parameters: food intake in the last 3 months, weight loss in the last 3 months, neuropsychological parameters, body mass index, use of other medications (more than three drugs), age, mobility, and the patient's own view of his/her health compared with other people of the same age. A score is assigned based on the severity of each parameter and a result of $\leq 14$ points was considered abnormal (Table 1).

The pivotal studies for cabazitaxel, abiraterone, enzalutamide and ${ }^{223} \mathrm{Ra}$ included patients over 75 years old $(18,25$,
Table 1 Parameters used to assess the health status of patients with prostate cancer
Items

A

A Has food intake declined over the past 3 months owing to loss of appetite, digestive problems, and difficulties with chewing or swallowing?

B Weight loss during the past 3 months

C Mobility

D Neuropsychological problems

E Body mass index

$\mathrm{F}$

Does the patient take more than 3 prescribed drugs per day?

G By comparison with other people of the same age, how does the patient consider his health status?

$\mathrm{H} \quad$ Age

Total score
Score for possible responses

$0=$ severe decrease in food intake

$=$ moderate decrease in food intake

$2=$ no decrease in food intake

$0=$ weight loss of $>3 \mathrm{~kg}$

$1=$ does not know

$2=$ weight loss $1-3 \mathrm{~kg}$

$3=$ no weight loss

$0=$ bed or chair bound

$1=$ able to get out of bed or chair but

does not go out

$2=$ goes out

$0=$ severe dementia or depression

$1=$ mild dementia

$2=$ no psychological problems

$0 \leq 19 \mathrm{~kg} / \mathrm{m}^{2}$

$1=19.0-20.9 \mathrm{~kg} / \mathrm{m}^{2}$

$2=21.0-22.9 \mathrm{~kg} / \mathrm{m}^{2}$

$3 \geq 23.0 \mathrm{~kg} / \mathrm{m}^{2}$

$0=$ yes

$1=$ no

$0=$ not as good

$0.5=$ does not know

$1.0=$ as good as others

$2.0=$ better than others

$0 \geq 85$ years

$1=80-85$ years

$0-17$ 
28 and 28\%, respectively). The benefit observed with these therapies was similar to that seen in younger patients, so age was not considered to be a risk factor [7-10]. In docetaxel studies, over $75 \mathrm{~s}$ also responded to treatment in the same way as the younger population [11].

As regards the toxicity of chemotherapy in the elderly population, the incidence of docetaxel-related fever, diarrhoea, anorexia, and peripheral oedema occurred at rates $\geq 10 \%$ higher in patients who were $\geq 75$ years of age versus $<65$ years [12]. According to the European expanded access study for cabazitaxel, this drug's adverse effects were more common among over $75 \mathrm{~s}$, with a higher rate of grade 3 neutropenia and greater use of granulocyte colony-stimulating factor (G-CSF), as well as a higher incidence of diarrhoea in the elderly population. Dose reduction and delay rates were similar in the over 70 and under 70 populations [13].

It can therefore be said that age alone is not a risk factor in these patients and the benefit provided is not very different from that obtained by younger patients. Age should only be considered in the context of other comorbidities and the patient's general condition.

\section{Performance status}

When evaluating a patient's performance status, it is necessary first to determine whether a particular parameter can be attributed to the malignancy itself or to some other type of disease or comorbidity. About $14 \%$ of patients with metastatic prostate cancer have a performance status of 2 or above [14].

Most clinical studies only include patients with a performance status of $0-1$ and exclude those with a higher score. In trials of cabazitaxel, abiraterone, enzalutamide and ${ }^{223} \mathrm{Ra}$, approximately $10 \%$ of patients enrolled had a performance status of 2. All four studies found a similar survival benefit in this patient group as in patients with a performance status of $0-1$ [7-10].

A meta-analysis of phase III studies analysed the efficacy of cabazitaxel, abiraterone and enzalutamide in 3149 prostate cancer patients who progressed after docetaxel therapy and had a performance status of 2 [15]. In the overall population analysed, the risk of death decreased by $31 \%$ in the experimental treatment arms [hazard ratio $(\mathrm{HR})=0.69 ; 95 \%$ confidence interval (CI) $0.63-0.76 ; p<0.001]$. In the 290 patients with a performance status of $2(9.2 \%$ of all patients evaluated), the risk of death fell by $26 \%$ in the experimental arms (HR $=0.74 ; 95 \%$ CI $0.56-0.98 ; p=0.035)$.

It can be concluded that patients with a performance status of 2 also benefit from these treatments. Even so, it is important to start therapy early, before a high-performance status score is reached, implying less benefit and worse survival.

\section{Comorbidities by system}

\section{Renal insufficiency}

Renal insufficiency is very common among patients with solid tumours. The Renal Insufficiency and Anticancer Medications (IRMA) study is a French observational trial that evaluated the prevalence of renal insufficiency in 4684 cancer patients [16]. According to the Cockcroft-Gault and abbreviated Modification of Diet in Renal Disease (aMDRD) formulae, 57.4 and $52.9 \%$ of patients, respectively, had abnormal renal function. Of these, 222 patients had prostate cancer, with a renal insufficiency rate of $62.6 \%$ (by the Cockcroft-Gault formula) and $55.9 \%$ (by the aMDRD formula) [17].

A little amount of docetaxel is eliminated via the kidneys. Only $6 \%$ of the administered dose is recovered unchanged in the urine [18]. Also, plasma docetaxel concentrations in patients on haemodialysis were found to resemble those in patients with normal kidney function, and therefore it can be safely administered either before or after the procedure [19].

Although the prevalence of renal insufficiency in prostate cancer patients is high, and some drugs used for managing them may be nephrotoxic or require dose adjustments, other treatments such as docetaxel, require no dose reduction. In the IRMA study, $43.2 \%$ of patients had received docetaxel treatment without any cases of nephrotoxicity being recorded [17]. Even so, several cases of renal insufficiency and renal failure have been reported. However, in approximately $20 \%$ of these cases there were no risk factors for acute renal failure, such as concomitant nephrotoxic medicinal products and gastrointestinal disorders [12].

\section{Hepatic insufficiency}

Hepatic insufficiency is an uncommon comorbidity in patients diagnosed with prostate cancer, with incidence rates of $0.2 \%$ for cirrhosis/chronic hepatitis and $0.06 \%$ for moderate/severe liver disease [20].

Docetaxel undergoes extensive hepatic metabolism via the cytochrome CYP3A pathway [21]. In observational and retrospective studies, docetaxel clearance was observed to be $12-38 \%$ lower in patients with abnormal plasma total bilirubin and/or transaminase levels [21].

The Child-Pugh score or classification is a useful method for staging the severity of hepatic dysfunction. However, it includes variables such as ascites, encephalopathy and elevated international normalised ratio (INR), which are not well-established predictors of docetaxel pharmacokinetics. According to this drug's summary of product characteristics, if serum bilirubin levels are above the upper limit of normal (ULN) and/or transaminase (AST/ALT) values exceed 3.5 times the ULN, associated with alkaline phosphatase values 
over 6 times that limit, a dose reduction cannot be recommended and docetaxel should not be used unless strictly indicated [12].

In the event of hepatic insufficiency, each case needs to be considered on an individual basis. This is because raised alkaline phosphatase or liver enzyme levels can occur as a consequence of bone metastases (common in prostate cancer patients) or liver metastases. To ascertain why these parameters are raised, tests can be ordered to identify their cause. When these enzyme levels are raised because of metastasis, docetaxel administration is not contraindicated, although the dose should be adjusted. If these enzyme levels are elevated for other reasons, use of this drug should be avoided.

\section{Neuropsychiatric disease}

Neuropathies are diseases that affect the central and peripheral nervous system. Although the term is often used as a synonym for peripheral neuropathy, the latter refers primarily to disorders affecting the peripheral nervous system. Polyneuropathy has a wide range of causes, from diabetes mellitus to alcohol abuse, human immunodeficiency virus (HIV) infection and chemotherapy. Several cytostatic agents may cause these neuropathies, including taxanes. The most frequent grade 3-4 neurotoxicity caused by docetaxel is peripheral sensory neuropathy, present in $1.2 \%$ of cases [12]. Clinical trials of these drugs have reported grade 2-4 peripheral neuropathy rates of $15-23 \%$ [22]. That incidence depends on various factors, such as dose per cycle, treatment regimen, duration of infusion, cumulative doses and, as mentioned above, comorbidities such as diabetes mellitus. It has been confirmed that severe peripheral neuropathy (grades 3 and 4), as defined by the Common Terminology Criteria for Adverse Events (CTCAE), mainly occurs with paclitaxel-based chemotherapy rather than docetaxel [23]. A retrospective analysis looked at the relationship between certain comorbidities (hypothyroidism, arterial hypertension, varicella-zoster virus infection, autoimmune disease, peripheral vascular disease and diabetes mellitus) and the risk of developing peripheral neuropathy in patients treated with taxanes [22]. It was found that only patients with diabetes mellitus, or underlying diabetic complications, had up to twice the risk of developing peripheral neuropathy, compared with non-diabetic patients. Moreover, those given paclitaxel were more likely to develop grade 2-4 peripheral neuropathy than those treated with docetaxel (25 versus $12 \%$, respectively). It was also observed that, for each age increment above 65 years, the risk of peripheral neuropathy rose by $4 \%$ [22]. The other comorbidities analysed did not show any association with the risk of developing peripheral neuropathy.

In another retrospective analysis, it was observed that the risk of developing peripheral neuropathy in taxane-treated patients diagnosed with diabetes mellitus more than 5 years earlier was higher than in non-diabetic patients [24]. Peripheral neuropathy rates were $48.8 \%$ in patients without diabetes mellitus, $52.8 \%$ in patients diagnosed with diabetes mellitus less than 5 years previously, and $75 \%$ in patients diagnosed with diabetes mellitus more than 5 years previously.

Based on the above evidence, for patients with a long history of diabetes mellitus, and peripheral neuropathy of grade 2 or above, docetaxel therapy is not considered suitable. However, this treatment could be considered in patients with peripheral neuropathy of up to grade 2 caused by another comorbidity.

\section{Cardiovascular disease}

Cardiovascular disease is the main cause of death in Western countries, and its prevalence rises with age. Although its origin is multifactorial, the most common risk factors predisposing to the development of cardiovascular conditions are ischaemic heart disease and cerebrovascular disease [25].

Most patients with advanced prostate cancer have had hormone therapy, which increases the risk of comorbidities including cardiovascular disease [26, 27]. Moreover, many treatments, including chemotherapy, can trigger serious cardiovascular events, especially in patients with underlying heart disease. This is due to the stress these drugs place on the body, by causing myelosuppression and because of their direct effects on the myocardium [28]. In fact, agents that act on microtubules, such as taxanes, have been linked to the development of arrhythmias and myocardial ischaemia [29].

Patients with heart failure or significantly reduced left ventricular ejection fraction (LVEF) treated with chemotherapy are at high risk of experiencing an episode of congestive heart failure or another serious cardiac event. Various assessment scales exist for patients with heart failure. The most widely used is the New York Heart Association (NYHA) functional classification. This defines 4 classes (I, II, III and IV) based on limitations to patients' physical activity imposed by cardiac symptoms [30]. This system can be used to assess severity of heart failure before deciding which anticancer treatment to administer.

Cancer, on the other hand, combined with a heart condition such as atrial fibrillation or heart failure, chemotherapy, dehydration and other factors related to malignant disease and its treatment, increases the risk of thromboembolic and cerebrovascular events. Accordingly, before chemotherapy is administered, the patient's past history of such conditions must be taken into account.

To identify patients at high risk of venous thromboembolic events, a predictive model was developed to stratify thromboembolic disease risk in cancer patients before starting chemotherapy, using clinical variables (tumour site, body mass index) and laboratory parameters (platelet and 
white blood cell counts, haemoglobin level) [31]. Other factors also related to the risk of developing thromboembolic disease were subsequently added, such as cancer stage, presence of a central venous catheter, and G-CSF use. Patients at high, intermediate and low risk were identified in this way [32].

Thus, all patients with metastatic prostate cancer and pre-existing cardiovascular disease (such as significantly reduced LVEF, heart failure, unstable angina, thromboembolic events, severe arrhythmia, etc.) should be individually assessed. This will enable careful choice of the anticancer treatment that entails the least risk of a serious cardiovascular event, by avoiding chemotherapy and using effective alternative treatments [33].

\section{Respiratory disease}

Respiratory comorbidities are often related to heart disease. Because of its frequency, the most prominent is chronic obstructive pulmonary disease (COPD), the incidence of which rises with age. This condition is not uncommonly encountered in patients with metastatic hormone-refractory prostate cancer, for whom taxanes are a treatment option.

Administering chemotherapy to patients with serious lung disease, such as severe COPD or pulmonary fibrosis, increases the risk of toxicity, because of these patients' functional limitations. There is also a greater risk of lung infections, which may be more severe as a consequence of neutropenia secondary to chemotherapy-induced myelosuppression [34].

It must also be remembered that one of the potential side effects of docetaxel is pulmonary toxicity, most commonly interstitial pneumonitis. Less frequently, non-cardiogenic pulmonary oedema and pleural effusion can occur, secondary to capillary leakage syndrome [35].

Accordingly, patients with disseminated prostate cancer and severe lung disease or pulmonary fibrosis are not eligible for taxane therapy, and other treatment options should be assessed.

\section{Nutritional status}

Of the various parameters to be taken into account when administering a therapy, nutritional status is one of the most important, because malnutrition is associated with increased mortality in cancer patients [36]. As this is a generally reversible abnormality, unless severe, it can be simply estimated by looking at weight loss in the last 3 months [37]. Good nutritional status is defined as $<5 \%$ weight loss in the last 3 months. Weight loss of $5-10 \%$ indicates moderate undernourishment, whereas $>10 \%$ weight loss is regarded as severe undernourishment $[4,6]$.
Nutritional status is therefore included among the 8 parameters evaluated in the SIOG recommendations, as one of the first two items to consider [4,6] (Table 1). Accordingly, if a patient has lost $>3 \mathrm{~kg}$ in the last 3 months, or is eating less, he/she would be deemed frail, and a non-chemotherapy treatment should be considered.

\section{Tools to evaluate frailty and toxicity}

In 2010, after conducting a systematic literature review, SIOG developed its guidelines for prostate cancer management in men over 70 years old [5, 37]. In 2017, a new multidisciplinary SIOG working group updated those recommendations [4]. The SIOG prostate cancer working group has established that elderly patients with this disease should be managed according to their health status, which is mainly determined by their comorbidities, not by chronological age $[4,5]$. Patients' health status affects both their survival and their treatment tolerance.

A validated, rapid, health status screening instrument can be used to identify patients who should undergo more thorough health evaluation, analysing comorbidities, nutritional status, and cognitive and physical functions. Screening can be performed using various scales, such as the Groningen Frailty Index [38], the Vulnerable Elders Survey-13 [39] and G8 [40]. The SIOG prostate cancer working group recommends systematic use of the G8 scale as a screening method, and an abnormal result strongly predicted 1-year mortality with a high sensitivity [41].

Another way to evaluate comorbidities is using the Cumulative Illness Score Rating-Geriatrics (CISR-G) [42]. This scale has been validated in cancer patients, and its prognostic performance correlates well with the Charlson index. Non-life-threatening comorbidities are also included according to their severity and control [43, 44]. Two scales are recommended for evaluating dependence level: activities of Daily Living (ADL), which rates a patient's ability to carry out activities of daily life; and Instrumental Activities of Daily Living (IADL), which measures a patient's skill at performing activities requiring a higher level of cognition $[40,45]$. The next step is to determine a patient's nutritional status by estimating weight loss and neuropsychological problems. Lastly, the possibility of resolving specific issues should be evaluated on an individual basis.

Following these recommendations, elderly patients with prostate cancer may be divided into three groups:

- Healthy or fit patients, who score over 14 on the G8 scale. These patients can tolerate, and therefore receive, standard treatment. 
- Vulnerable patients with reversible impairment, whose G8 score is 14 or lower. These patients should receive standard treatment after medical intervention.

- Frail patients with non-reversible impairment, scoring 14 or lower on the G8 scale. These patients might benefit from geriatric intervention, including comprehensive geriatric assessment, and could receive adapted treatment.

The SIOG expert panel advises that, by following their algorithm, which depends on whether a patient is deemed fit or unfit for docetaxel therapy, the standard docetaxel chemotherapy regimen $\left(75 \mathrm{mg} / \mathrm{m}^{2}\right.$ every 3 weeks) is appropriate for fit and vulnerable elderly patients, while an alternative regimen can be used in frail patients $[4,6]$.

The CRASH score finds different risk of development of chemotherapy toxicity evaluating diastolic blood pressure, IADL score, LDH value, scheme of chemotherapy, ECOG-PS, Mini Mental Health Status and Mini Nutritional assessment, with different scores to hematologic and nonhematologic toxicities [46].

Another model for predicting chemotherapy toxicity was developed by Hurria et al. (CARG, Cancer and Aging Research Group) They ponder age of patient, cancer type, planned chemotherapy dose, planned number of chemotherapy drugs, haemoglobin level, creatinine clearance (by Jeliffe, ideal weight), hearing, presence of falls in the past 6 months, capability of taking their own medicines, capability of walk and social activities. They classify the risk in low, medium and high to develop chemotherapy toxicity $[47,48]$.

In 2016, a comparison was made among CARG tool, VES-13 and oncologist judgment to predict toxicities greater or equal than grade 3 in men who underwent chemotherapy for metastatic prostate cancer, but no differences among them were found to predict the risk of toxicity [49].

\section{Absolute contraindications}

The main contraindications for docetaxel are neuropathy, dementia, allergic reactions, previous severe toxicity including hypersensitivity to the drug, uncontrolled serious disease (infectious, inflammatory, autoimmune, etc.). Absolute contraindications include serum neutrophil count $<1500 / \mu$, hypersensitivity to the drug and severe hepatic insufficiency.

Absolute contraindications for docetaxel also include poor general condition (performance status 3 and most patients with performance status 2). Relative contraindications, with a recommendation for special precautions for its use, include comorbidities unrelated to prostate cancer, and frailty as defined by an appropriate geriatric evaluation (according to SIOG recommendations), because the adverse effects will be exacerbated in patients with any of these profiles [50].

\section{Defining the unfit patient}

Defining a patient with castration-resistant prostate cancer as unfit for docetaxel therapy relies on the health professional's clinical assessment of performance status, with no age restrictions but with appropriate geriatric assessment using the ADL and IADL scales as well as evaluating the patient's comorbidities and nutritional status. Hence, patients with a performance status of 2 or above, or a poor geriatric assessment, would be unfit for treatment. This is the right time to identify patients whose general condition and comorbidities might or might not be improved by some medical intervention. These patients might subsequently become fit for treatment.

Other patients unfit for docetaxel therapy are those with severe hepatic insufficiency (by the Child-Pugh classification), severe interstitial lung disease or severe COPD, over $10 \%$ weight loss in the preceding 3 months, heart failure of NYHA class III or above, or frailty by the SIOG G8 scale. Figure 1 provides details of the treatment algorithm for patients with castration-resistant prostate cancer, according to whether they are unfit or fit, elder vulnerable or frail for docetaxel therapy.

\section{Alternative treatment regimens for unfit patients}

Based on results published in 2004, docetaxel became the first agent to have an impact on the prognosis of castrationresistant prostate cancer, and thus the first standard of care in this clinical scenario [51, 52]. Nevertheless, the patients included in those publications do not represent "real-world" patients, because, as in any phase III study, only selected patients were assessed. The role of docetaxel in terms of safety and efficacy in unfit patients therefore cannot be deduced from the results obtained. There is very little information about this, and the publications available only analysed this scenario in elderly patients, because up to $75 \%$ of cancer patients aged 75 years or above are classed as unfit for docetaxel treatment [53].

Several clinical studies have suggested that weekly docetaxel regimens reduce the incidence of myelosuppression, so these might be more appropriate for frail patients $[54,55]$. One article describes a multicentre, retrospective evaluation of 175 elderly men with castration-resistant prostate cancer treated with a standard regimen of docetaxel administered every 3 weeks, or an adapted regimen. In most cases, this was weekly and involved doses of 


\section{Patient with metastatic castration- resistant prostate cancer \\ Patient unfit for docetaxel (any criterion)}

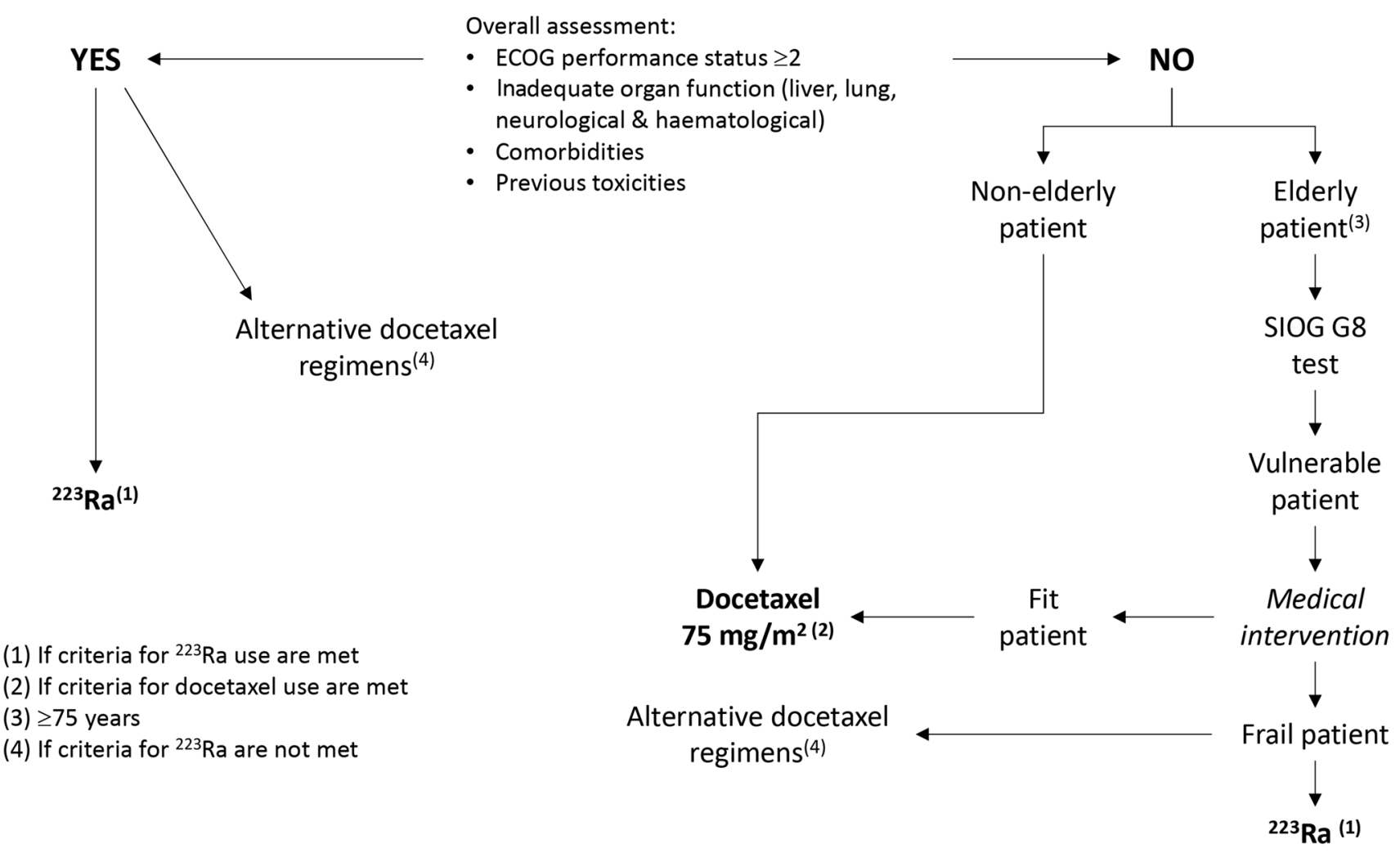

Fig. 1 Treatment algorithm

$30-35 \mathrm{mg} / \mathrm{m}^{2}$ [56]. The study report does not say whether patients' general condition was taken into account when assigning the type of treatment regimen. However, patients treated with an adapted regimen had higher median age ( $>80$ years: $41.2 \%$ on adapted regimen versus $25.3 \%$ on standard regimen; $p<0.05)$, worse performance status (performance status $>2: 27.5 \%$ on adapted regimen versus $13.7 \%$ on standard regimen; $p<0.05)$ and reported a higher daily intake of analgesics (62.5\% on adapted regimen versus $42.1 \%$ on standard regimen; $p<0.05$ ) than those treated with the standard regimen. The occurrence of serious adverse events was found to be significantly correlated with worse performance status. There was more haematological toxicity on the standard regimen, with a higher rate of neutropenia and febrile neutropenia, whereas more fatigue occurred with the adapted regimen. There were no differences in prostate-specific antigen (PSA) levels between the two groups. The overall response rate showed no statistically significant differences between the standard regimen and the adapted regimen (40 versus $43 \%$, respectively; $p=0.96$ ).

The design and retrospective nature of this study make it difficult to draw conclusions. Based on its results, however, the authors recommended performing a geriatric evaluation and assessing adapted docetaxel regimens in unfit or frail patients.

A randomised phase II study prospectively evaluated the role of docetaxel every 3 weeks (cycle 1: $60 \mathrm{mg} / \mathrm{m}^{2}$; subsequent cycles: $\left.70 \mathrm{mg} / \mathrm{m}^{2}\right)$ or weekly $\left(35 \mathrm{mg} / \mathrm{m}^{2}\right.$ days 1 and 8 every 3 weeks) in elderly patients considered vulnerable or frail according to the SIOG classification $[57,58]$. The trial included 66 patients at 21 sites. It was closed prematurely on the safety committee's recommendation because of an excess of deaths caused by toxicity in frail patients. The authors therefore concluded that neither treatment regimen is feasible in patients of this type. However, another study prospectively compared a regimen involving docetaxel $75 \mathrm{mg} / \mathrm{m}^{2}$ every 3 weeks against one 
consisting of docetaxel $50 \mathrm{mg} / \mathrm{m}^{2}$ on days 1 and 14 every 4 weeks in 360 patients with hormone-refractory prostate cancer [59]. Greater toxicity, mainly of a haematological nature, was observed on the 3-weekly regimen. It was concluded that the biweekly regimen is better tolerated and can be considered as an option for elderly patients too unfit or frail for the standard docetaxel regimen.

On the other hand, ${ }^{223} \mathrm{Ra}$ has demonstrated an improvement in overall survival in patients unfit for docetaxel in a phase III study [HR 0.69 (95\% CI 0.52-0.92)] showing a very good safety profile, with anaemia and thrombocytopenia as the main toxicities (14 and 6\% of grade 3-4 events, respectively) $[10,60]$.

Based mainly on the absence of any firm recommendations for alternative docetaxel regimens, we recommend that the use of ${ }^{223} \mathrm{Ra}$ be assessed as the first option for frail or unfit patients, provided they meet the criteria for receiving it. If they fail to meet those criteria, alternative docetaxel regimens should be assessed.

\section{Conclusions}

A patient with prostate cancer should be assessed for optimisation of the available treatments, especially chemotherapy. Given that health status affects not only the survival of these patients but also their tolerance of the treatments used, it is very important for this parameter to be assessed. While health status appears not to be affected by age, it is influenced by comorbidities. That means analysing comorbidities, nutritional status, and cognitive and physical functions.

Whereas docetaxel is suitable for fit and vulnerable patients, due to the absence of firm recommendations for alternative docetaxel regimens, we recommend that ${ }^{223} \mathrm{Ra}$ be assessed as the first option in frail or unfit patients, provided they meet the criteria for receiving it. If they fail to meet those criteria, given the high probability of toxicity and the expected resultant lack of efficacy, we recommend that alternative docetaxel regimens should be assessed. The biweekly regimen is better tolerated and suitable for unfit or frail elderly patients.

Acknowledgements The authors wish to thank Dr. Fernando Sánchez Barbero from HealthCo S.L. (Madrid, Spain) for his help in the preparation of the first draft of this manuscript. Bayer Spain provided comment on the first draft of this manuscript, but thereafter the authors made all the decisions about its contents.

Author contribution All authors have participated in the analysis and interpretation of data, drafting of the first version of the manuscript, revising critically subsequent versions and approving the final version of the manuscript before submission.

\section{Compliance with ethical standards}

Conflict of interest Urbano Anido-Herranz, Natalia Fernández-Nuñez, Lucía Santomé-Couto, Martín Lázaro-Quintela and Ovidio Fernandez-Calvo declare that they do not have any conflict of interest. Ana Medina-Colmenero and Sergio Vázquez-Estévez declare their participation in advisory boards of Bayer, Astellas, Janssen and Sanofi. Javier Afonso-Afonso declares his contribution to advisory boards of Janssen, Sanofi, Roche, Bristol-Myers Squibb and Merck Sharp \& Dohme.

Ethical approval The analysis in this article is based on previously conducted studies, and does not involve any new studies of human or animal subjects performed by any of the authors.

Informed consent Informed consent was obtained from all participants.

Open Access This article is distributed under the terms of the Creative Commons Attribution 4.0 International License (http://creativeco mmons.org/licenses/by/4.0/), which permits unrestricted use, distribution, and reproduction in any medium, provided you give appropriate credit to the original author(s) and the source, provide a link to the Creative Commons license, and indicate if changes were made.

\section{References}

1. Ferlay J, Soerjomataram I, Dikshit R, Eser S, Mathers C, Rebelo $\mathrm{M}$, et al. Cancer incidence and mortality worldwide: sources, methods and major patterns in GLOBOCAN 2012. Int J Cancer. 2014;136:E359-86.

2. Albertsen PC, Li H, Lu-Yao GL. Impact of comorbidity on survival among men with localized prostate cancer. J Clin Oncol. 2011;29:1335-41.

3. Ferlay J, Steliarova-Foucher E, Lortet-Tieulent J, Rosso S, Coebergh JWW, Comber H, et al. Cancer incidence and mortality patterns in Europe: estimates for 40 countries in 2012. Eur J Cancer. 2013;49:1374-403.

4. Droz J-P, Boyle H, Albrand G, Mottet N, Puts M. Role of geriatric oncologists in optimizing care of urological oncology patients. Eur Urol Focus. 2017;3:385-94.

5. Droz J-P, Balducci L, Bolla M, Fitzpatrick JM, Joniau S, Kat$\tan \mathrm{MW}$, et al. Management of prostate cancer in older men: recommendations of a working group of the International Society of Geriatric Oncology. Manag Prostate Cancer Older Men. 2010;106:462-9.

6. Droz J-P, Aapro M, Balducci L, Boyle H, Van den Broeck T, Cathcart $\mathrm{P}$, et al. Management of prostate cancer in older patients: updated recommendations of a working group of the International Society of Geriatric Oncology. Lancet Oncol. 2014;15:e404-14.

7. Scher HI, Fizazi K, Saad F, Taplin ME, Sternberg CN, Miller K, et al. Increased survival with enzalutamide in prostate cancer after chemotherapy. N Engl J Med. 2012;367:1187-97.

8. de Bono JS, Logothetis CJ, Molina A, Fizazi K, North S, Chu L, et al. Abiraterone and increased survival in metastatic prostate cancer. N Engl J Med. 2011;364:1995-2005.

9. de Bono JS, Oudard S, Ozguroglu M, Hansen S, Machiels JP, Kocak I, et al. Prednisone plus cabazitaxel or mitoxantrone for metastatic castration-resistant prostate cancer progressing after docetaxel treatment: a randomised open-label trial. Lancet. 2010;376:1147-54.

10. Parker C, Nilsson S, Heinrich D, Helle SI, O’Sullivan JM, Fossa $\mathrm{SD}$, et al. Alpha emitter radium-223 and survival in metastatic prostate cancer. N Engl J Med. 2013;369:213-23. 
11. Berthold DR, Pond GR, Soban F, de Wit R, Eisenberger M, Tannock IF. Docetaxel plus prednisone or mitoxantrone plus prednisone for advanced prostate cancer: updated survival in the TAX 327 study. J Clin Oncol. 2008;26:242-5.

12. Docetaxel product information (Taxotere ${ }^{\circledR}$, Aventis Pharma). http://www.ema.europa.eu/docs/en_GB/document_library/ EPAR_-_Product_Information/human/000073/WC50003526 4.pdf. Accessed 05 June 2017.

13. Heidenreich A, Bracarda S, Mason M, van Oort I, Papandreou C, Fossa S, et al. Safety of cabazitaxel in senior adults with metastatic castration-resistant prostate cancer: results of the European compassionate-use programme. Eur J Cancer. 2014;50:1090-9.

14. Armstrong AJ, Garrett-Mayer E, de Wit R. Prediction of survival following first-line chemotherapy in men with castration-resistant metastatic prostate cancer. Clin Cancer Res. 2010;16:203-11.

15. Iacovelli R, Altavilla A, Procopio G, Bracarda S, Santoni M, Cascinu $\mathrm{S}$, et al. Are post-docetaxel treatments effective in patients with castration-resistant prostate cancer and performance of 2 ? A meta-analysis of published trials. Prostate Cancer Prostatic Dis. 2013;16:323-7.

16. Launay-Vacher V, Oudard S, Janus N, Gligorov J, Pourrat X, Rixe $\mathrm{O}$, et al. Prevalence of renal insufficiency in cancer patients and implications for anticancer drug management: the renal insufficiency and anticancer medications (IRMA) study. Cancer. 2007;110:1376-84.

17. Launay-Vacher V, Ayllon J, Janus N, Spano JP, Ray-Coquard I, Gligorov J, et al. Drug management of prostate cancer: prevalence and consequences of renal insufficiency. Clin Genitourin Cancer. 2009;7:E83-9.

18. Extra JM, Rousseau F, Bruno R, Clavel M, Le Bail N, Marty M. Phase I and pharmacokinetic study of Taxotere (RP 56976; NSC 628503) given as a short intravenous infusion. Cancer Res. 1993;53:1037-42.

19. Mencoboni M, Olivieri R, Vannozzi MO, Schettini G, Viazzi F, Ghio R. Docetaxel pharmacokinetics with pre- and post-dialysis administration in a hemodyalized patient. Chemotherapy. 2006;52:147-50.

20. Edwards BK, Noone AM, Mariotto AB, Simard EP, Boscoe FP, Henley SJ, et al. Annual Report to the Nation on the status of cancer, 1975-2010, featuring prevalence of comorbidity and impact on survival among persons with lung, colorectal, breast, or prostate cancer. Cancer. 2014;120:1290-314.

21. Tran A, Jullien V, Alexandre J, Rey E, Rabillon F, Girre V, et al. Pharmacokinetics and toxicity of docetaxel: role of CYP3A, MDR1, and GST polymorphisms. Clin Pharmacol Ther. 2006;79:570-80.

22. Hershman DL, Till C, Wright JD, Awad D, Ramsey SD, Barlow WE, et al. Comorbidities and risk of chemotherapyinduced peripheral neuropathy among participants 65 years or older in southwest oncology group clinical trials. J Clin Oncol. 2016;34:3014-22.

23. Lee JJ, Swain SM. Peripheral neuropathy induced by microtubulestabilizing agents. J Clin Oncol. 2006;24:1633-42.

24. Kus T, Aktas G, Kalender ME, Sevinc A, Kul S, Suner A, et al. Taxane-induced peripheral sensorial neuropathy in cancer patients is associated with duration of diabetes mellitus: a single-center retrospective study. Support Care Cancer. 2016;24:1175-9.

25. Olalla MT, Medrano MJ, Sierra MJ, Almazán J. Time trends, cohort effect and spatial distribution of cerebrovascular disease mortality in Spain. Eur J Epidemiol. 1999;15:331-9.

26. Jespersen CG, Norgaard M, Borre M. Androgen-deprivation therapy in treatment of prostate cancer and risk of myocardial infarction and stroke: a nationwide Danish population-based cohort study. Eur Urol. 2014;65:704-9.
27. Keating NL, O'Malley AJ, Smith MR. Diabetes and cardiovascular disease during androgen deprivation therapy for prostate cancer. J Clin Oncol. 2006;24:4448-56.

28. Ewer MS, Ewer SM. Cardiotoxicity of anticancer treatments: what the cardiologist needs to know. Nat Rev Cardiol. 2010;7:564-75.

29. Yeh ET, Tong AT, Lenihan DJ, Yusuf SW, Swafford J, Champion $\mathrm{C}$, et al. Cardiovascular complications of cancer therapy: diagnosis, pathogenesis, and management. Circulation. 2004;109:3122-31.

30. Hurst JW, Morris DC, Alexander RW. The use of the New York Heart Association's classification of cardiovascular disease as part of the patient's complete problem list. Clin Cardiol. 1999;22:385-90.

31. Khorana AA, Kuderer NM, Culakova E, Lyman GH, Francis CW. Development and validation of a predictive model for chemotherapy-associated thrombosis. Blood. 2008;111:4902-7.

32. Moore RA, Adel N, Riedel E, Bhutani M, Feldman DR, Tabbara $\mathrm{NE}$, et al. High incidence of thromboembolic events in patients treated with cisplatin-based chemotherapy: a large retrospective analysis. J Clin Oncol. 2011;29:3466-73.

33. Albini A, Pennesi G, Donatelli F, Cammarota R, De Flora S, Noonan DM. Cardiotoxicity of anticancer drugs: the need for cardiooncology and cardio-oncological prevention. J Natl Cancer Inst. 2010;102:14-25.

34. Lyman GH, Lyman $\mathrm{CH}$, Agboola O. Risk models for predicting chemotherapy-induced neutropenia. Oncologist. 2005;10:427-37.

35. Raufi A, Dotson J, Khasawneh M. Acute respiratory distress syndrome after treatment of metastatic prostate cancer with taxotere: a case report and literature review. Case Rep Urol. 2015;2015:198381.

36. Blanc-Bisson C, Fonck M, Rainfray M, Soubeyran P, BourdelMarchasson I. Undernutrition in elderly patients with cancer: target for diagnosis and intervention. Crit Rev Oncol Hematol. 2008;67:243-54.

37. Droz JP, Balducci L, Bolla M, Emberton M, Fitzpatrick JM, Joniau S, et al. Background for the proposal of SIOG guidelines for the management of prostate cancer in senior adults. Crit Rev Oncol Hematol. 2010;73:68-91.

38. Baitar A, van Fraeyenhove F, Vandebroek A, De Droogh E, Galdermans D, Mebis J, et al. Evaluation of the Groningen Frailty Indicator and the G8 questionnaire as screening tools for frailty in older patients with cancer. J Geriatr Oncol. 2013;4:32-8.

39. Luciani A, Ascione G, Bertuzzi C, Marussi D, Codecà C, Di Maria G, et al. Detecting disabilities in older patients with cancer: comparison between comprehensive geriatric assessment and vulnerable elders survey-13. J Clin Oncol. 2010;28:2046-50.

40. Lawton MP, Brody EM. Assessment of older people: self-maintaining and instrumental activities of daily living. Gerontologist. 1969;9:179-86.

41. Soubeyran P, Bellera C, Goyard J, Heitz D, Curé H, Rousselot $\mathrm{H}$, et al. Screening for vulnerability in older cancer patients: the ONCODAGE prospective multicenter cohort study. PLoS One. 2014;9:e115060-20.

42. Miller MD, Paradis CF, Houck PR, Mazumdar S, Stack JA, Rifai $\mathrm{AH}$, et al. Rating chronic medical illness burden in geropsychiatric practice and research: application of the Cumulative Illness Rating Scale. Psychiatry Res. 1992;41:237-48.

43. Extermann M. Geriatric assessment with focus on instrument selectivity for outcomes. Cancer J. 2005;11:474-80.

44. Pompei P, Charlson ME, Ales K, MacKenzie CR, Norton M. Relating patient characteristics at the time of admission to outcomes of hospitalization. J Clin Epidemiol. 1991;44:1063-9.

45. Katz S, Ford AB, Moskowitz RW, Jackson BA, Jaffe MW. Studies of illness in the aged. The index of ADL: a standardized measure of biological and psychosocial function. JAMA. 1963;185:914-9. 
46. Extermann M, Boler I, Reich RR, Lyman GH, Brown RH, DeFelice $\mathrm{J}$, et al. Predicting the risk of chemotherapy toxicity in older patients: the chemotherapy risk assessment scale for high-age patients (CRASH) score. Cancer. 2011;118:3377-86.

47. Hurria A, Mohile S, Gajra A, Klepin H, Muss H, Chapman A, et al. Validation of a prediction tool for chemotherapy toxicity in older adults with cancer. J Clin Oncol. 2016;34:2366-71.

48. Hurria A, Togawa K, Mohile SG, Owusu C, Klepin HD, Gross CP, et al. Predicting chemotherapy toxicity in older adults with cancer: a prospective multicenter study. J Clin Oncol. 2011;29:3457-65.

49. Alibhai SM, Aziz S, Manokumar T, Timilshina N, Breunis H. A comparison of the CARG tool, the VES-13, and oncologist judgment in predicting grade $3+$ toxicities in men undergoing chemotherapy for metastatic prostate cancer. J Geriatr Oncol. 2017:8:31-6.

50. Maroto P, Solsona E, Gallardo E, Mellado B, Morote J, Arranz JA, et al. Expert opinion on first-line therapy in the treatment of castration-resistant prostate cancer. Crit Rev Oncol Hematol. 2016;100:127-36.

51. Petrylak DP, Tangen CM, Hussain MH, Lara PN Jr, Jones JA, Taplin ME, et al. Docetaxel and estramustine compared with mitoxantrone and prednisone for advanced refractory prostate cancer. N Engl J Med. 2004;351:1513-20.

52. Tannock IF, de Wit R, Berry WR, Horti J, Pluzanska A, Chi KN, et al. Docetaxel plus prednisone or mitoxantrone plus prednisone for advanced prostate cancer. N Engl J Med. 2004;351:1502-12.

53. Basso U, Tonti S, Bassi C, Brunello A, Pasetto LM, Scaglione $\mathrm{D}$, et al. Management of frail and not-frail elderly cancer patients in a hospital-based geriatric oncology program. Crit Rev Oncol Hematol. 2008;66:163-70.

54. Beer TM, Berry W, Wersinger EM, Bland LB. Weekly docetaxel in elderly patients with prostate cancer: efficacy and toxicity in patients at least 70 years of age compared with patients younger than 70 years. Clin Prostate Cancer. 2003;2:167-72.

55. Fossa SD, Jacobsen AB, Ginman C, Jacobsen IN, Overn S, Iversen $\mathrm{JR}$, et al. Weekly docetaxel and prednisolone versus prednisolone alone in androgen-independent prostate cancer: a randomized phase II study. Eur Urol. 2007;52:1691-8.

56. Italiano A, Ortholan C, Oudard S, Pouessel D, Gravis G, Beuzeboc $\mathrm{P}$, et al. Docetaxel-based chemotherapy in elderly patients (age 75 and older) with castration-resistant prostate cancer. Eur Urol. 2009;55:1368-75.

57. Irelli A, Bruera G, Cannita K, Palluzzi E, Gravina GL, Festuccia $\mathrm{C}$, et al. Bioclinical parameters driving decision-making of subsequent lines of treatment in metastatic castration-resistant prostate cancer. Biomed Res Int. 2014;2014:909623.

58. Mourey L, Gravis G, Sevin E, Priou F, Bompas E, Sarda C, et al. Feasibility of docetaxel-prednisone (DP) in frail elderly (age 75 and older) patients with castration-resistant metastatic prostate cancer (CRMPC): GERICO10-GETUG P03 trial led by unicancer. J Clin Oncol. 2014;32:152.

59. Hervonen P, Joensuu H, Joensuu T, Ginman C, McDermott R, Harmenberg U, et al. Biweekly docetaxel is better tolerated than conventional three-weekly dosing for advanced hormone-refractory prostate cancer. Anticancer Res. 2012;32:953-6.

60. Hoskin P, Sartor O, O'Sullivan JM, Johannessen DC, Helle SI, Logue J, et al. Efficacy and safety of radium-223 dichloride in patients with castration-resistant prostate cancer and symptomatic bone metastases, with or without previous docetaxel use: a prespecified subgroup analysis from the randomised, double-blind, phase 3 ALSYMPCA trial. Lancet Oncol. 2014;15:1397-406. 